Macfarlane, I. (1958). J. gen. Microbiol. 18, 720-732

\title{
A Solution-Culture Technique for Obtaining Root-Hair, or Primary, Infection by Plasmodiophora brassicae
}

\author{
BY I. MACFARLANE \\ Rothamsted Experimental Station, Harpenden, Hertfordshire
}

\begin{abstract}
SUMMARY: Primary infections were obtained by growing cabbage seedlings in a modified Hoagland's solution in which resting spores of Plasmodiophora brassicae Woron. were suspended. Seeds were germinated on filter paper wet with tap water, and after 2 days the plants were transferred to small glass tubes bent in the form of a shallow $U$ or to small vials containing solution and spores. Zoosporangia were formed after several days growth at $25^{\circ}$ in the dark. They were stained in aceto-carmine. A roughly linear relationship was found between the logarithm of number of infections/root and the logarithm of spore concentration in the medium. Numbers of infections were usually greater at $1 / 5$ or $1 / 25$ dilution of the culture solution than at the standard concentration, but were very much fewer or none in more dilute $1 / 125$ or more concentrated $(\times 5)$ solutions. The concentration which permitted maximal infection tended to vary from one experiment to another. Infection was not affected by changing from $\mathrm{pH} 5$ to 6 but was greatly decreased at $\mathrm{pH} 8$.
\end{abstract}

There is abundant evidence that Plasmodiophora brassicae Woron., the parasitic slime mould which causes the clubroot disease of crucifers, survives by means of the many spores it produces in the clubroot galls. When the gall decays, the spores are released into the soil where they may persist for many years. So far as is known, all new infections originate from these resting spores, so that factors which affect their infectivity are fundamental to any study of the parasitism of Plasmodiophora brassicae. Two kinds of test have been used in investigating the effects of environment on infection by $\boldsymbol{P}$. brassicae. The older, and formerly the only, method is to enumerate or make observations on plants which develop clubroot symptoms when grown for several weeks in infested soil. The second method is based on the early stages of the life cycle of the parasite in roots of seedlings which have been grown for a few days in an infested medium. When a resting spore germinates in a situation favouring infection, the zoospore that escapes enters a root hair of the host plant and there develops into a group of zoosporangia. On a length of root, these groups or sori of zoosporangia can be stained and infections readily recognized and counted (Samuel \& Garrett, 1945).

As there are two motile stages in the life cycle of Plasmodiophora brassicae, it will be convenient to call the zoospores which emerge from resting spores, primary zoospores and those from zoosporangia in the root hairs, secondary zoospores. Infection by a primary zoospore will be called primary infection or, as formerly, root-hair infection. The stages of the life cycle between the discharge of the zoosporangia and the formation of the plasmodia in the growing gall are unknown, but there is no evidence that infections by resting spores ever develop in any way other than to zoosporangia first. This is supported 
by the fact that the number of primary infections is affected qualitatively by soil conditions in much the same way as is the number of clubbed plants (Samuel \& Garrett, 1945). Both methods seem to give a measure of infection from resting spores, but this is true only in so far as clubbing depends on primary infection. Factors, such as variation in host and pathogen, can influence or determine the development of clubs independently of the number of primary infections (Macfarlane, 1955). In this connexion we may recall that $\boldsymbol{P}$. brassicae, although not known to complete its life cycle except on crucifers, can infect and form zoosporangia in various non-crucifers. Pryor (1940) showed that mineral nutrition of the host also affected the development of clubs, and there is some evidence that it can do so after the zoosporangial stage (Macfarlane, 1952). These considerations make it clear that each kind of test has a different range of application. For evaluating effects of environment on primary infection alone, the method of counting zoosporangial sori in root hairs is clearly the appropriate one. The present paper is concerned with the development of this technique. In earlier work primary infections were obtained by growing plants in soil, but for physiological studies this is too complex and simpler media are needed so that conditions can be more precisely defined. A method has therefore been evolved for infecting seedlings growing in nutrient solution. This paper describes the method, and some of the factors which affect the number of primary infections in these cultures.

\section{METHODS}

Host plant. Cabbage, horticultural variety 'King of Hearts' (Ryder \& Sons Ltd., St Albans), was used in all experiments. Seeds were germinated on filter-paper, supported above and dipping into tap water in a $14 \mathrm{~cm}$. Petri dish, and incubated in the dark at $25^{\circ}$ for 48 or $60 \mathrm{hr}$. depending on the batch of seed. The radicles were then $5-10 \mathrm{~mm}$. long and the seedlings could be fairly easily handled. Plants were selected by eye for uniformity; when size differences could not be eliminated in this way, seedlings of all grades were allocated to each experimental treatment.

Culture solution. The mineral nutrient solution for culture of seedlings was that described by Hoagland \& Snyder (1934), but with the phosphate concentration doubled. The composition of the standard solution was thus $(\mathrm{M})$ : $\mathrm{Ca}\left(\mathrm{NO}_{3}\right)_{2}, 0.005 ; \mathrm{KNO}_{3}, 0.005 ; \mathrm{MgSO}_{4}, 0.002 ; \mathrm{KH}_{2} \mathrm{PO}_{4}, 0.002$. For convenience this solution will be referred to as $\mathrm{S}$ solution and other concentrations as $5 \mathrm{~S}, \mathrm{~S} / 5, \mathrm{~S} / 10$ and so on. The $\mathrm{pH}$ value of the $\mathrm{S}$ solution, measured with a glass electrode, was $5 \cdot 0$. The reaction of the solution was altered by supplying the standard amount of phosphate as appropriate proportions of $\mathrm{KH}_{2} \mathrm{PO}_{4}$ and $\mathrm{K}_{2} \mathrm{HPO}_{4}$. Doing this inevitably altered the potassium content, and when all the phosphate was given as the dibasic salt, it was changed to the maximum extent, viz., 1.3 times the standard amount. All culture solutions were made up with glass-distilled water, which had been equilibrated with the atmosphere with respect to dissolved gases by aeration overnight with air drawn from outside the building. 
Inoculum. Resting spores of Plasmodiophora brassicae were obtained from clubroot galls grown in a warm greenhouse. Cabbage seedlings were planted when 2-3 days old in a mixture of 1 vol. loam soil to 3 vol. sand ( $\mathrm{pH}$ of 5.56.0) in ordinary flower pots. Inoculum of crushed clubroot galls of spore suspension was poured on to the soil surface. The soil was kept wet and mineral nutrients were supplied in solution. Clubs were harvested about 6-8 weeks after inoculation. Most experiments were done with an isolate of $\boldsymbol{P}$. brassicae which had been maintained on cabbage in the greenhouse for many years. In one experiment an isolate from Agdell field, Rothamsted, multiplied variously on cabbage and turnip, was used. These isolates are called I and II, respectively.

Maturation of the spores is apparently complete and extraction of spores easiest when the gall is beginning to decompose (see also Ayers, 1944). At this stage the cut surface of a gall usually has a grey or marbled appearance. After thorough washing and removal of fibrous roots, galls were finely ground in a mortar or macerated in a blender (MSE Atomix) with water. The brei was then filtered through muslin and, when necessary, the fluid was expressed by hand. The many spores which adhered to the muslin were discarded, but the pulp was resuspended in water and the extraction process repeated. The spores were washed in distilled water by centrifugation at least twice and usually five times. They were stored as dense suspensions in the refrigerator at 3-4. Spores have been kept in this way for over 3 years now without serious loss of viability; Bremer, Wehnelt \& Brandenburg (1937) also stored inoculum in this way.

The concentration of spores in suspensions was determined by haemocytometer counts made on appropriate dilutions. Spores in some suspensions tended to clump, making counting inaccurate or impossible, but they dispersed when suspended in weak alkali (e.g. $0.01 \mathrm{~N}-\mathrm{NaOH}$ ) instead of in water. Suspensions for use were made by diluting stock suspension in aerated water.

Technique for obtaining primary or root-hair infections. In attempting to improve the root-hair infection technique, the first modification tried was to replace the soil + sand medium (Macfarlane, 1952) by sand alone. Enough S/5 solution containing spores was added to acid-washed sand to bring its water content to $80 \%$ saturation. In other respects the original method was followed. Many infections were obtained in this way, and sand cultures were employed successfully in some experiments, but the lower layers of the sand tended to become waterlogged, which restricted root growth. Pryor (1940), who used sand culture to get clubbed plants, avoided this difficulty by using an intermittent siphoning arrangement with a continuous drip nutrient supply. With an organism like Plasmodiophora brassicae, which has a free-swimming stage, solution culture seemed the simple and obvious method. In early experiments, however, when seedlings were supported on cork rafts floating on $\mathrm{S} / 5$ solution + spores in a beaker, infection failed. Seedlings were infected by growing them between glass slides and filter paper soaked in a suspension of spores in S/5 solution, but this method was not used much because the variable extent to which plants pushed the paper from the glass affected results. Woronin (1878) infected seedlings by placing them in spore suspension in watch glasses; 
this was repeated with $\mathrm{S} / 5$ solution, and numerous, though somewhat sporadic, infections were obtained. As proximity to the spores, which quickly settle to the bottom, and possibly a small volume, may have favourably influenced infection in the watch glass as compared with the beaker, small glass tubes, $75 \mathrm{~mm} . \times 5-6 \mathrm{~mm}$. internal diameter, bent in a shallow U-shape and open at both ends, were made for single plants. They were supported horizontally in racks cut from aluminium sheet. Vials, with dimensions $50 \mathrm{~mm} . \times 8.5 \mathrm{~mm}$. diameter, were also used. In the shallow U-tubes, seedlings were held in position by loose cotton wool plugs; in the vials they were supported on fine mesh stainless-steel gauze in which holes large enough for the roots had been punched with a stout needle. Abundant infections were obtained in these vessels. Seedlings in the infection tubes were kept in a moist chamber in the dark at 24-25 . Early stages of infection have been seen $36 \mathrm{hr}$. after setting up and zoosporangia were usually formed by the third or fourth day. After incubation for 4-6 days, roots were removed to aceto-carmine (Samuel \& Garrett, 1945), which was made by adding $1 \mathrm{~g}$. carmine to $100 \mathrm{ml}$. boiling $45 \%(\mathrm{v} / \mathrm{v})$ acetic acid in water, filtering and diluting to $300 \mathrm{ml}$. with water.

\section{Evaluation of results}

Counting infections. Roots were mounted in water on a slide ruled at intervals to aid counting and examined microscopically with a $16 \mathrm{~mm}$. objective and $\times 10$ ocular. Constant change of focus was necessary to see all infections in root hairs lying on either side of the root. All infections seen were counted, including those in rhizodermal cells other than root hairs, either on a selected part of the root or, more usually, along the whole length. Counting infections along the whole root has the advantage of avoiding variations in susceptibility in different parts of the root (i.e. at different times during the growth of the root) which may be caused by experimental treatments. On the other hand, if root growth were arrested at an early stage, there might be fewer infections on the root simply because of a lack of cells. On balance, however, it seems simpler to regard the whole root as the unit which, as it were, traps parasites and to leave the question of the effectiveness of the trap for later analysis. Each group of zoosporangia was regarded as the consequence of a single infection, and where two or more distinct groups were seen in one cell they were counted as separate infections. No observations were made on the plasmodia from which zoosporangia developed to see whether they fused or not, but as apparent multiple infections were more numerous when there were very many infections, the separate sori probably indicate separate infections. This supports the view of Ayers (1944) who, from observations on infected roothairs, concluded that plasmodia in the hairs did not fuse.

Statistical analysis. The standard errors of number of infections/plant for separate groups of observations were proportional to the group means. Before subjecting results to analysis of variance they were therefore transformed to a logarithmic function. The transformation $\log (x+c)$, where $x=$ number of infections and $c$ is a constant, was tried on the results of several 
experiments and the scatter diagrams of standard errors plotted against group means were inspected. With $c=1$ the transformation tended to over-correct and a more satisfactory value of $c$ seemed to lie somewhere between 10 and 25 . Standard errors of groups with low means tended to be unduly low however, and, following Kleczkowski (1955), the transformation

$$
z=\log _{10} \frac{1}{2}\left[x+c+\sqrt{ }\left(x^{2}+2 c x\right)\right]
$$

was substituted. When $c=20$, this transformation satisfactorily eliminated error dependence on the mean. Values of $z$ were obtained directly from Kleczkowski's table. For some experiments, values of $c$ other than 20 were better, and for one standard errors were independent of the mean when $c=1$. The practical alternative to determining the best value of $c$ for the results of every experiment is to select a value that seems to be generally suitable. Thus, in analysing the experiments described here, the value 20 was chosen. The graphs are based on actual numbers of infections and in one table both actual numbers of infections and transformed values are given. The term 'least significant difference' is sometimes abbreviated to 'L.S.D.'

\section{RESULTS}

\section{Effect of spore concentration}

Previously, when plants were infected in soil, a linear relationship was found between the logarithm of the mean number of infections on a segment of root and the logarithm of the spore concentration in the inoculum. A roughly similar relationship has now been found for plants infected in solution cultures. The results of several experiments are shown in Figs. 1 and 2 with both numbers of infections and spore concentration plotted on logarithmic scales. The points in Figs. 1 and $2 \mathrm{~A}$ indicate numbers of infections $/ 2 \mathrm{nd} \mathrm{cm}$. of root and/whole root, respectively, of plants infected in S/5 solution; those in Fig. $2 B$ indicate infection on whole roots infected in $\mathbf{S}$ solution. The similar trends of the two groups of curves in Figs. 1 and $2 \mathrm{~A}$, which are based on different experiments, suggest that comparable results might be obtained by counting infections on either $1 \mathrm{~cm}$. of root or on the whole root. When plants were infected in $\mathrm{S} / 5$ solution convenient numbers of infections for counting, say 50-300 infections/plant, were obtained by spore concentrations of $2 \times 10^{5}-$ $2 \times 10^{6} / \mathrm{ml}$. when only $1 \mathrm{~cm}$. was examined and by $5 \times 10^{2}-5 \times 10^{3} \mathrm{spores} / \mathrm{ml}$. when the whole root was examined. The number of infections obtained with a given concentration of spores, however, varied considerably from one spore suspension to another and from one experiment to another. Similarly, although when plants were in $\mathrm{S}$ solution higher spore concentrations were usually necessary to obtain the same number of infections that were obtained in S/5 solution, this effect was not invariable.

\section{Effect of concentration of the culture solution}

The results summarized in Fig. 3 and Table 1 show that this factor is important. Relative numbers of infections at different concentrations are shown in Fig. 3 as means over all experiments. In general, infection was suppressed 
at high concentrations of the culture solution and slightly less so at very low concentrations, with a high peak in numbers of infections at an intermediate level towards the dilute end of the scale. Table 1 shows that the response to changes in the concentration of the solution varied from one experiment to another. Infections were consistently fewer in the most dilute and in the most concentrated, than in other solutions. In $\mathrm{S}$ solution there were fewer infections than in $\mathrm{S} / 5$ solution in six experiments, in one there was no difference and in another there were actually more than in the dilute solution. Compared with

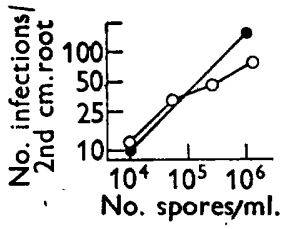

Fig. 1

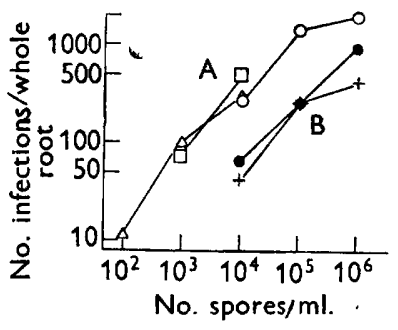

Fig. 2

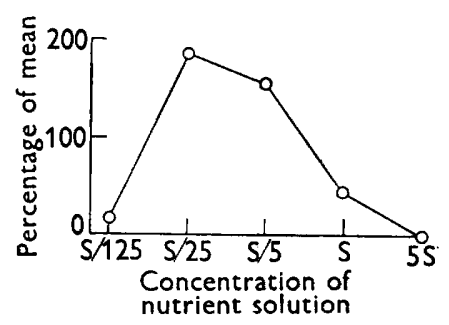

Fig. 3

Figs. 1 and 2. Effect of spore concentration on numbers of infections. Fig. 1. Cabbage seedlings infected in $\mathrm{S} / 5$ solution, $\mathrm{pH} 6$. Two experiments: $\bigcirc$ with 8 replicates and with 5 replicates. Fig. 2. (A), cabbage seedlings in $\mathrm{S} / 5$ solution, $\mathrm{pH} 6 ;(\mathrm{B})$, in $\mathrm{S}$ solution, pH 6. Four experiments: $\bigcirc$ with 5 replicates. These points show the means of actual nos. infections in Expt. 8, Table 1. Means of transformed nos. infections are given in the table. $\square$, with 12 replicates; $\triangle$, with 10 replicates; + , with 12 replicates.

Fig. 3. Effect of concentration of the culture solution on numbers of infections. For each experiment, the no. infections/plant at any one concentration of the culture solution and at any one spore concentration, was expressed as a percentage of the mean for that spore concentration. The graph shows means of these percentages over all experiments.

\section{Table 1. Effect of concentration of the culture solution on numbers of infections}

Except in Expt. 5, cabbage seedlings were infected in solution cultures and infections were counted along the whole root. In Expt. 5 plants were infected in sand cultures with six replicate pots/treatment and 5 plants/pot and infections were counted on the 1 st and 2 nd $\mathrm{cm}$. of root. Dash = not tested.

\begin{tabular}{|c|c|c|c|c|c|c|c|c|}
\hline \multirow[b]{2}{*}{ Expt. } & \multirow{2}{*}{$\begin{array}{l}\text { Spores } \\
\text { (no./ml.) }\end{array}$} & \multicolumn{5}{|c|}{$\begin{array}{l}\text { Means of transformed nos. infections/plant. } \\
\text { Concentration of solution }\end{array}$} & \multirow{2}{*}{$\begin{array}{c}\text { Least } \\
\text { significant } \\
\text { difference } \\
(P=0 \cdot 05)\end{array}$} & \multirow{2}{*}{$\begin{array}{l}\text { No. of } \\
\text { replicates }\end{array}$} \\
\hline & & $\mathrm{S} / 125$ & $\mathrm{~S} / 25$ & $\mathrm{~S} / \mathbf{5}$ & $\mathbf{S}$ & $5 \mathrm{~S}$ & & \\
\hline 1 & $2.5 \times 10^{5}$ & - & $2 \cdot 65$ & $2 \cdot 61$ & $2 \cdot 14$ & 1.03 & $0 \cdot 22$ & 12 \\
\hline 2 & $10^{5}$ & - & $1 \cdot 85$ & $2 \cdot 95$ & 1.59 & 1.07 & 0.40 & 4 \\
\hline $\mathbf{3}$ & $5 \times 10^{3}$ & - & $2 \cdot 26$ & 1.85 & $1 \cdot 11$ & 1.00 & 0.30 & 10 \\
\hline 4 & $5 \times 10^{3}$ & 1.07 & $1 \cdot 46$ & 1.81 & $1 \cdot 11$ & 1.00 & 0.20 & 20 \\
\hline 5 & $4 \times 10^{5}$ & $1 \cdot 46$ & $1 \cdot 70$ & 1.98 & - & - & 0.20 & 6 \\
\hline 6 & $5 \times 10^{4}$ & - & - & $2 \cdot 47$ & $2 \cdot 69$ & 一 & 0.49 & 5 \\
\hline 7 & $10^{4}$ & - & - & 1.83 & $2 \cdot 42$ & - & 0.34 & 10 \\
\hline \multirow[t]{3}{*}{8} & $10^{4}$ & - & - & $2 \cdot 46$ & 1.84 & - & 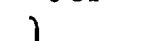 & \\
\hline & $10^{5}$ & - & - & $3 \cdot 11$ & $2 \cdot 37$ & - & 0.31 & 5 \\
\hline & $10^{6}$ & - & - & $\mathbf{3 \cdot 2 5}$ & $2 \cdot 95$ & - & & \\
\hline \multirow[t]{2}{*}{9} & $5 \times 10^{3}$ & 1.04 & $1 \cdot 77$ & $1 \cdot 27$ & $1 \cdot 12$ & $1 \cdot 00$ & \multirow{2}{*}{0.24} & \multirow[b]{2}{*}{7} \\
\hline & $2.5 \times 10^{4}$ & $1 \cdot 30$ & $2 \cdot 16$ & $2 \cdot 28$ & 1.04 & 1.00 & & \\
\hline
\end{tabular}


S/25 solution there were also usually fewer infections in S except once when there was no difference. In the six experiments in which infection at concentrations $S / 5$ and $S / 25$ was compared, there was no difference in one; infection was greater in $S / 5$ solution in three experiments and greater in $S / 25$ in two. Within an experiment, variation of spore load sometimes influenced the effect of concentration of the solution. Thus in Table 1, Expt. 8, the difference in numbers of infections in $S$ compared with $S / 5$ solution was smallest at the highest spore concentration and was just no longer significant at the $\mathbf{5} \%$ probability level. As there were many infections at this spore load, it might be argued that the available infection sites under those particular conditions were becoming saturated. Something similar seems to have happened in Expt. 9, but at a lower level of infection and at different concentrations of the solution. Thus at the lower spore concentration there were far more infections in $\mathbf{S} / 25$ solution than in any other, but with more spores the number of infections in $S / 25$ solution was equalled by that in $S / 5$ solution. Under the conditions of this experiment, however, infection in $\mathrm{S}$ solution was not affected by an increase in spore concentration.

Some plants grown in the most dilute solution $\mathrm{S} / \mathbf{1 2 5}$ had dead cells over much of the root and dead root tips with laterals growing out behind, symptoms which strongly indicate calcium deficiency. Most plants had produced roots several $\mathrm{cm}$. long before the tips died. Similar effects were occasionally seen on roots grown in $\mathbf{S} / 25$ solution. Roots grown in $S / 5, S$ and $5 \mathrm{~S}$ solutions showed no obvious differences from one another.

In some solutions, changing the concentration also changed the $\mathrm{pH}$ value and in some experiments there was a gradient of $\mathrm{pH}$ values corresponding to a gradient in numbers of infections. The regression of numbers of infections on initial $\mathrm{pH}$ value determined on data from four experiments was, however, not significant $(P=0 \cdot 09)$. Except for one $5 \mathrm{~S}$ solution at $\mathrm{pH} 4 \cdot 6$, all $\mathrm{pH}$ values lay between $5 \cdot 3$ and $6 \cdot 4$. As shown in the next section, it seems unlikely that differences in $\mathrm{pH}$ of this magnitude influence infection.

\section{Effect of $\mathrm{pH}$ value}

Numbers of infections at three $\mathrm{pH}$ values, 5,6 and 7 , by two different isolates of Plasmodiophora brassicae are shown in Table 2. Isolate I was more infective than isolate II, but both were affected similarly by changes in $\mathrm{pH}$ value. At $\mathrm{pH} 7$ infection was depressed relative to that in the other solutions, confirming the general view that infection by $\boldsymbol{P}$. brassicae is favoured by acid conditions. Infections did not differ at pH 5 and 6.

Study of the effects of $\mathrm{pH}$ value itself on primary infection is complicated by other changes in the medium inevitably occasioned by alteration of acidity. The most important of these is probably the precipitation of calcium phosphate in the neutral and alkaline region, thus changing the concentration of both calcium and phosphate. Also, spores might be imprisoned in such precipitates. Other difficulties are the changes in $\mathrm{pH}$ value caused by the growing plants and the limitations on buffering imposed by the impossibility of growing plants in solutions of very high salt content. In an experiment in which 
infection at three concentrations of both acid and alkaline potassium phosphate was compared, an attempt was made to avoid large precipitates of calcium phosphate(s) by having in addition to one with the usual concentration a series with a very low concentration of calcium. Phosphate concentrations were increased above the standard concentration, $0.002 \mathrm{M}$, (S) to increase buffering

Table 2. Effect of $\mathrm{pH}$ value of culture solution on root-hair infection of cabbage seedlings by two isolates of Plasmodiophora brassicae

Plants infected in $\mathrm{S}$ solution containing $5 \times 10^{4}$ spores $/ \mathrm{ml}$., in shallow U-tubes. Five replicates. pH values at end of experiment determined on bulked solutions from the five replicate tubes. L.S.D.= least significant difference.

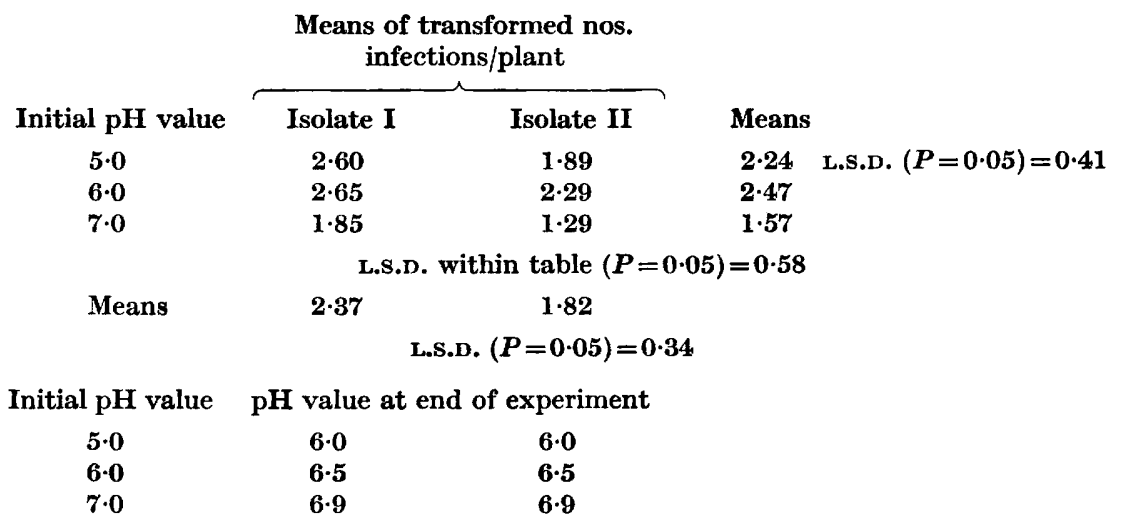

capacity. Results and $\mathrm{pH}$ measurements are given in Table 3, which also indicates those alkaline solutions in which visible precipitates developed. There was no consistent effect of calcium on infection so the values for these treatments have been pooled. Measurements of $\mathrm{pH}$ value showed that, in the short duration of this experiment (4 days), buffering was reasonably adequate. The greatest change recorded was 1.3 units in the low acid-phosphate + high calcium solution. At the high concentration of the alkaline phosphate the seedling roots died; they grew at this concentration of the acid phosphate, but there was no infection. Results were therefore obtained from the medium and low (standard) phosphate treatments. Infection was depressed both by high pH values and concentration of phosphate above the standard. Thus, phosphate concentration had an effect similar to that caused by changes in the concentration of the rest of the solution, and the effect of $\mathrm{pH}$ value was again as expected. The effect of $\mathrm{pH}$ value was significantly greater at the medium than at the low phosphate concentration. The question then arises whether this result is actually due to differences in $\mathrm{pH}$ value. The removal of spores in calcium phosphate precipitates was probably unimportant. If removal of spores by sedimentation were a complicating factor, the results were the opposite of what would be expected, because spores settle more quickly in acid than in alkaline solutions. Differences in potassium content were small in comparison with changes in $\mathrm{pH}$ value. On the other hand, factors like $\mathrm{CO}_{2}$ content, known to depend on $\mathrm{pH}$, were not taken into account; nor were 
changes in calcium known. Even at this lower concentration of calcium, the formation of nuclei of calcium phosphate at $\mathrm{pH} 8$ would be virtually certain (Bjerrum, 1949), so that the concentration of free calcium ion might be considerably changed, although no precipitate was seen. The role of calcium in solutions of different $\mathrm{pH}$ value thus remains problematical.

\section{Table 3. Effect of $\mathrm{pH}$ value and potassium phosphate concentration on numbers of infections}

Cabbage seedlings infected in solution cultures. The basal solution contained $0.005 \mathrm{M}$ $\mathrm{KNO}_{3}$ and $0.002 \mathrm{M}-\mathrm{MgSO}_{4}$. Either $\mathrm{KH}_{2} \mathrm{PO}_{4}$ or $\mathrm{K}_{2} \mathrm{HPO}_{4}$ was added to $0.002 \mathrm{M}, 0.0067 \mathrm{M}$ or $0.02 \mathrm{M}$ and $\mathrm{CaCl}_{2}$ to $0.0005 \mathrm{M}$ or $0.005 \mathrm{M}$. The low phosphate + high calcium solution thus corresponded to S solution with $\mathrm{CaCl}_{2}$ instead of $\mathrm{Ca}\left(\mathrm{NO}_{3}\right)_{2}$. Spore concentration $10^{6} / \mathrm{ml}$. Four replicate U-tubes. Values for the calcium treatments have been pooled in the tables of nos. infections so that each figure is based on eight replicates. $\mathrm{pH}$ values at the end of the experiment were determined on bulked solutions from the four replicate tubes.

\begin{tabular}{|c|c|c|}
\hline \multicolumn{3}{|c|}{ Mean no. infections/plant } \\
\hline $\begin{array}{c}\text { Phosphate } \\
\text { concentration (M) }\end{array}$ & $\mathrm{KH}_{\mathbf{8}} \mathrm{PO}_{4}$ & $\mathrm{~K}_{\mathbf{2}} \mathrm{HPO}$ \\
\hline 0.0200 & $\mathbf{0}$ & Roots died \\
\hline $0 \cdot 0067$ & 503 & $\theta$ \\
\hline 0.0020 & 2750 & 537 \\
\hline \multicolumn{3}{|c|}{ Means of transformed nos. infections/plant } \\
\hline 0.0067 & $2 \cdot 66$ & 1.30 \\
\hline 0.0020 & $\mathbf{3} \cdot 36$ & $2 \cdot 61$ \\
\hline
\end{tabular}

\begin{tabular}{|c|c|c|c|c|}
\hline \multirow[b]{2}{*}{$\underset{(\mathrm{M})}{\mathrm{KH}_{2} \mathbf{P O}}$} & \multirow[b]{2}{*}{$\mathrm{CaCl}_{\mathbf{2}}$} & \multicolumn{2}{|c|}{ pH values } & \multirow[b]{2}{*}{$\begin{array}{l}\text { Visible precipitation } \\
\text { of calcium phosphates }\end{array}$} \\
\hline & & Initial pH & Final pH & \\
\hline 0.0200 & $\begin{array}{l}\text { High } \\
\text { Low }\end{array}$ & $\begin{array}{l}4.85 \\
4.80\end{array}$ & $\begin{array}{l}5 \cdot 35 \\
5 \cdot 35\end{array}$ & \multirow{4}{*}{ None } \\
\hline 0.0067 & $\begin{array}{l}\text { High } \\
\text { Low }\end{array}$ & $\begin{array}{l}5 \cdot 00 \\
5 \cdot 00\end{array}$ & $\begin{array}{l}5 \cdot 55 \\
5 \cdot 85\end{array}$ & \\
\hline 0.0020 & $\begin{array}{l}\text { High } \\
\text { Low }\end{array}$ & $\begin{array}{l}5 \cdot 00 \\
5 \cdot 05\end{array}$ & $\begin{array}{l}6 \cdot 30 \\
5 \cdot 85\end{array}$ & \\
\hline$\underset{(\mathrm{M})}{\mathrm{K}_{2} \mathrm{HPO}_{4}}$ & & & & \\
\hline 0.0200 & $\begin{array}{l}\text { High } \\
\text { Low }\end{array}$ & $\begin{array}{l}8 \cdot 10 \\
8 \cdot 60\end{array}$ & $\begin{array}{l}8 \cdot 25 \\
\mathbf{8 \cdot 2 0}\end{array}$ & $\begin{array}{l}\text { Precipitate } \\
\text { None }\end{array}$ \\
\hline 0.0067 & $\begin{array}{l}\text { High } \\
\text { Low }\end{array}$ & $\begin{array}{l}7 \cdot 40 \\
8 \cdot 00\end{array}$ & $\begin{array}{l}7 \cdot 70 \\
7 \cdot 90\end{array}$ & $\begin{array}{l}\text { Precipitate } \\
\text { Slight precipitate }\end{array}$ \\
\hline 0.0020 & $\begin{array}{l}\text { High } \\
\text { Low }\end{array}$ & $\begin{array}{l}7 \cdot 20 \\
7 \cdot 40\end{array}$ & $\begin{array}{l}7 \cdot 00 \\
7 \cdot 30\end{array}$ & $\begin{array}{l}\text { Precipitate } \\
\text { None }\end{array}$ \\
\hline
\end{tabular}

The technique described for obtaining root-hair infections by Plasmodiophora brassicae in solution cultures has a number of advantages over the soil method described by Samuel \& Garrett (1945). Solutions can be standardized and are more easily handled than soils, and the slow process of washing out roots from soil is avoided. Uniformly shaped vials are readily obtainable and the shallow U-tubes can be made at least fairly uniform. Each tube with its seedling is the 
unit of replication and as tubes or vials in their racks occupy relatively little space large experiments can be easily set up with as many replications as are necessary to give the precision desired. The principal drawback to all quantitative studies of primary infection is the labour of making the microscopical counts. It is therefore important to arrange that the mean number of infections is in a convenient range. Unfortunately, the considerable variation in numbers of infections which often occurs on different occasions, even with the same preparation of spores, makes the achievement of this condition uncertain. If the technique is to be fully exploited, this difficulty must be overcome. Some modification of the method of raising seedlings now seems likely to lead to improvements in this respect. At present it has been found convenient to use the $\mathrm{S} / 5$ solution for most experiments but if the method of preparing the seedlings were changed, another concentration of the culture solution might prove to be better. The method is obviously convenient for studying the early stages of the parasite in the root and the external factors which influence infection. Apart from the advantages already claimed and the simplicity of the infection medium there is probably little to choose between this method and that of Samuel \& Garrett for such purposes as measuring the infectivity of variously treated spores and the preliminary testing of possible fungicides against $\boldsymbol{P}$. brassicae. It also suggests ways of handling the organism which might be useful for life-cycle studies. For example, experience in infecting plants from resting spores in vitro should be valuable when investigating the behaviour of secondary zoospores. Finally, a technique such as this should help to achieve and use spores free from the contaminating micro-organisms which are such a serious nuisance in many kinds of work.

The results obtained when the concentration of the culture solution was varied have done little more than define the effect of this factor on infection. Obvious questions, e.g. whether one or more ion species in particular are always concerned or whether different ions are involved at different parts of the concentration range, whether the effect is on host or on parasite and what causes the variation between different experiments, remain unanswered. It may therefore be useful to discuss some of the lines of approach suggested by the above and other work. The signs of calcium deficiency in the roots grown in the very dilute solutions suggest that the decline in numbers of infections in this concentration range may be due to some effect on the host cells in which calcium is involved. The particular variations that were made in calcium content of solutions did not appear to have much effect on infection. In the sand-culture experiment (Table 1, Expt. 5) there were three solutions with different ratios of calcium to other ions, calcium being replaced by sodium. Each of these solutions was then tested at the three dilutions shown. There was a suggestion, though little more, that infections were fewer when calcium concentrations were low. Over the concentration range $S / 25$ to $S$ there was even less evidence about the effect of calcium. Changing the calcium concentration to one-tenth of the standard concentration had no consistent effect on infection (Table 3). At concentrations greater than the standard, the total salt concentrations attained and the effects caused by various treatments, 
together with some data from the experiments of Samuel \& Garrett (1945), are shown in Table 4.

That making the concentration of the culture solution $5 \mathbf{S}$ or adding spores to soil in $0 \cdot 1 \mathrm{~N}$-sodium or potassium chlorides suppressed infection suggests an effect not associated with a particular ion and hence perhaps due to the osmotic pressure of the solution. It is conjectured that Plasmodiophora brassicae might perhaps be affected by this. Potassium phosphate (Table 4)

\section{Table 4. Effect of salt concentration on numbers of infections obtained} in solution culture and soil culture

Based on: (1) experiments quoted in Tables 1 and 3 , in which plants were infected in solution culture; (2) experiments of Samuel \& Garrett (1945) who added salts to spore suspensions which were then mixed with soil. Brassica seedlings were grown in the inoculated soils to obtain primary infections.

\begin{tabular}{|c|c|c|c|c|}
\hline & $\begin{array}{l}\text { Basal } \\
\text { medium }\end{array}$ & $\begin{array}{l}\text { Salt(s) } \\
\text { added }\end{array}$ & $\begin{array}{l}\text { Final total salt } \\
\text { concentration in } \\
\text { culture solution } \\
\text { or spore } \\
\text { suspension (g./l.) }\end{array}$ & $\begin{array}{l}\text { Effect on } \\
\text { nos. of } \\
\text { infections } \\
\text { relative to } \\
\text { respective } \\
\text { standard }\end{array}$ \\
\hline Present experiments & S solution & $\begin{array}{l}\text { None } \\
\text { All basal (5S) } \\
\mathrm{KH}_{2} \mathrm{PO}_{4}\end{array}$ & $\begin{array}{l}1 \cdot 837 \\
9 \cdot 185 \\
2 \cdot 612\end{array}$ & $\begin{array}{l}\text { Standard } \\
\text { Decrease } \\
\text { Decrease }\end{array}$ \\
\hline $\begin{array}{l}\text { Samuel \& Garrett } \\
(\mathbf{1 9 4 5 )}\end{array}$ & $\begin{array}{l}\text { Water + spores } \\
\text { (added to soil) }\end{array}$ & $\begin{array}{l}\text { None } \\
0 \cdot 01 \mathrm{~N}-\mathrm{NaCl} \\
0 \cdot 01 \mathrm{~N}-\mathrm{KCl} \\
0 \cdot 01 \mathrm{~N}-\mathrm{CaCl} \\
0 \cdot 10 \mathrm{~N}-\mathrm{NaCl} \\
0 \cdot 10 \mathrm{~N}-\mathrm{KCl}\end{array}$ & $\begin{array}{l}0 \cdot 000 \\
0 \cdot 585 \\
0 \cdot 745 \\
0 \cdot 555 \\
\mathbf{5} \cdot 850 \\
7 \cdot 450\end{array}$ & $\begin{array}{l}\text { Standard } \\
\text { None } \\
\text { None } \\
\text { None } \\
\text { Decrease } \\
\text { Decrease }\end{array}$ \\
\hline
\end{tabular}

depressed infection with only a small increase in salt concentration. Perhaps potassium phosphate was more inhibitory than other salts or perhaps the response of infection to increasing salt concentration was merely beginning to be more pronounced at this concentration. The effect of increasing salt concentrations from $\mathrm{S} / 5$ upwards is strikingly similar to that obtained by Smith \& Walker (1941) with Aphanomyces euteiches on peas. They ascribed the whole phenomenon to effects of salt nutrition on the pea host.

Recently, Palm \& McNew (1956), from results of experiments in which crucifer seedlings were infected with Plasmodiophora brassicae in sand culture, reported that the number of primary infections was markedly affected by the calcium content of the nutrient solutions. Numbers of infections usually reached a maximum when the calcium content was $2 \mathrm{mg}$.equiv./l. (also the concentration of calcium in $\mathrm{S} / 5$ solution) and fell off rather steeply on either side of the peak. They also stated, without elaboration, that the calcium concentration at which infection reached a peak, depended on the concentrations of other ions. The similarity of these results to those obtained in the present experiments by changing the concentration of the whole solution is clear. In the present experiments, however, the concentration which permitted maximum infection differed on different occasions. This variation, and the fact that maximum infection could be at such widely different concentrations as $\mathbf{S} / \mathbf{2 5}$ 
and $S$ makes one suspect that there is one underlying mechanism, at least until the highest concentrations are reached. Some factor at present uncontrolled must be involved and it seems possible that it may operate during the pretreatment of the seedlings. Seeds were germinated in tap water which in Harpenden contains, among other things, large amounts of calcium bicarbonate. It is possible that the assumption underlying the use of tap water for this purpose, namely, that variations in its content of dissolved material, whether calcium salts or other substances, were unimportant, may prove to be erroneous. These problems are being investigated. The possibility that calcium may be a factor in infection by $\boldsymbol{P}$. brassicae is of especial interest in view of the participation of this element in the structure of all plant cell-walls and its important, if somewhat complex, effects on the growth of roots.

As it is virtually impossible to alter the $\mathrm{pH}$ value of the culture solution without varying other quantities some uncertainty must remain about the effect of $\mathrm{pH}$ on infection. There can be little doubt that it was the change of $\mathrm{pH}$ of the culture solution from 5 to 8 and not alterations of potassium content which depressed infection. This is in agreement with the demonstration by Samuel \& Garrett (1945) that the inhibitory effect of lime and other alkalis on infection by Plasmodiophora brassicae in the soil is due, directly (or indirectly in the case of carbonates) to the addition of hydroxyl ions and not of the eations. In spite of this, Palm \& NcNew (1956), on the basis of their sandculture experiments, again raised the old and much debated question as to whether the effect of lime in controlling clubroot is in any way due to the calcium added. I do not think that it has yet been shown that adding calcium has an effect at all comparable to that which is obtained by adding alkalis and is generally believed to be caused by high $\mathrm{pH}$ values. But in any of the media that have been used for infection tests, changing the $\mathrm{pH}$ value even from slightly acid to slightly alkaline will also change the amount of free calcium ion. Thus, in nutrient solutions containing phosphates, the precipitation of calcium phosphate(s) in the alkaline region makes it difficult if not impossible to disentangle changes in $\mathrm{pH}$ from changes in free calcium content. In soils the situation must be more complex. These changes might or might not have effects on the plant and on infection but they do make it impossible to control the experimental conditions.

\section{REFERENCES}

Ayers, G. W. (1944). Studies on the life history of the clubroot organism, Plasmodiophora brassicae. Canad. J. Res. C, 22, 143.

BJERRUM, N. (1949). Investigations on the solubility of calcium phosphate. In Selected Papers. Copenhagen : Einar Munksgaard.

Bremer, H., Wehnelt, B. \& Brandenburg, E. (1937). Zur Prüfung von Bekämpfungsmitteln gegen Kohlhernie. Mitt. biol. ZentAnst., Berl. 55, 61.

Hoagland, D. R. \& SNYDER, W. C. (1934). Nutrition of strawberty plant under controlled conditions: (a) Effects of deficiencies of boron and certain other elements: (b) Susceptibility to injury from sodium salts. Proc. Amer. Soc. hort. Sci. 30, 288.

KLECzKowsKI, A. (1955). The statistical analysis of plant virus assays : a transformation to include lesion numbers with small means. J. gen. Microbiol. 13, 91. 
Macfarlane, I. (1952). Factors affecting the survival of Plasmodiophora brassicae Wor. in the soil and its assessment by a host test. Ann. appl. Biol. 39, 239.

Macfarlane, I. (1955). Variation in Plasmodiophora brassicae Woron. Ann. appl. Biol. 43, 297.

PALM, E. T. \& McNew, G. L. (1956). A method for determining the incidence of clubroot infection in nutrient cultures. Contrib. Boyce Thompson Inst. 18, 333.

Pryor, D. E. (1940). The effect of some mineral nutrients on the development of clubroot of crucifers. J. agric. Res. 61, 149.

SaMUel, G. \& GarReTt, S. D. (1945). The infected root hair count for estimating the activity of Plasmodiophora brassicae Woron. in the soil. Ann. appl. Biol. 32, 96.

SmIth, P. G. \& WALKer, J. C. (1941). Certain environal and nutritional factors affecting Aphanomyces root rot of garden pea. J. agric. Res. 63, 1.

Woronin, M. (1878). Plasmodiophora brassicae, Urheber der Kohlpflanzen-Hernie. Jb. wiss. Bot. 11, 548.

(Received 30 December 1957) 